\title{
P I9-35. Replicating adenovirus type 5 host range recombinant vaccine biodistribution in rhesus macaques following multiple mucosal routes of immunization
}

\author{
J Patterson*1, Q Li ${ }^{2}$, S Kuate ${ }^{1}$, K McKinnon ${ }^{1}$, J DiPasquale ${ }^{1}$, AT Haase ${ }^{2}$ and \\ M Robert-Guroff ${ }^{1}$
}

Address: ${ }^{1}$ National Cancer Institute, Bethesda, MD, USA and ${ }^{2}$ University of Minnesota Medical School/Dept. of Microbiology, Minneapolis, MN, USA

* Corresponding author

from AIDS Vaccine 2009

Paris, France. 19-22 October 2009

Published: 22 October 2009

Retrovirology 2009, 6(Suppl 3):P355 doi:10.1 186/1742-4690-6-S3-P355

This abstract is available from: http://www.retrovirology.com/content/6/S3/P355

(C) 2009 Patterson et al; licensee BioMed Central Ltd.

\section{Background}

Intranasal/intratracheal (IN/IT) priming with replicating adenovirus type 5 host range mutant (Ad5hr)-SIV recombinant vaccines plus envelope protein boosting elicits potent, durable protection in rhesus macaques following SIV $_{\text {mac251 }}$ challenge. The recent STEP trial outcome prompted us to examine cell types infected, tissue distribution and persistence of E3-deleted Ad5hr in vivo.

\section{Methods}

Ad5hr-SIVenv/rev, -SIVgag, and -GFP recombinants were given to rhesus macaques by the IN/IT, sublingual, rectal or vaginal routes at weeks 0 and 12. Controls received Ad5hr-GFP only. Blood, bronchial alveolar lavage (BAL), and rectal biopsies were collected one week after each Ad immunization (weeks 1 and 13) and examined for GFP expression among lymphocytes (CD3, CD4, CD8, B, NK), macrophages, dendritic and epithelial cells by flow cytometry. Two weeks post each Ad (weeks 2 and 14), select macaques were sacrificed and multiple tissues fixed for later histochemical staining. Flow analyses were also expanded at necropsy to include jejunum, tonsils and lymph nodes.

\section{Results}

At week 1, GFP was expressed in BAL and rectal macrophages and epithelial cells in all macaques, regardless of immunization route, but was undetectable at week 2 . In contrast, more potent and sustained expression of GFP was detected at both 13 and 14 weeks in high percentages of macrophages, but not epithelial cells, in PBMCs, rectum, jejunum and BAL, with expansion to BAL mDCs, again irrespective of route.

\section{Conclusion}

Overall, the route of immunization did not impact the level or location of $\mathrm{Ad} 5 \mathrm{hr}$ replication in the macaque model. Ad5hr serum neutralizing antibody was detected after the first and boosted after the second Ad immunization primarily in the IN/IT group, but did not affect GFP expression or persistence within macrophages. It may have played a role in loss of GFP expression in epithelial cells after the second Ad. Measurement of SIV-specific immunity and histochemical staining for Ad in tissues is ongoing. 